\title{
Tiene [la] palabra la víctima pura[?] El vacío social, el testimonio y la desesperación del investigador ante el sufrimiento sin forma ni lenguaje
}

Has the pure victim got voice? The social vacuum. the testimony and the investigator's desperation in front of the suffering without form not even language

\section{GABRIEL GATTI}

UNIVERSIDAD DEL PAÍS VASCO·g.gatti@ehu.eus

Profesor titular de sociología, Universidad del País Vasco. Dirige el proyecto "Mundo(s) de víctimas” (MICINN, CSO 2011-22451), enseña teoría sociológica e investiga sobre las formas de construcción de identidad en situaciones marcadas por fuertes vulneraciones de los derechos humanos y/o quiebras en el sentido moderno de la idea de ciudadanía. Sobre eso ha enseñado, conversado y publicado en varios lugares y momentos (EHESS, CES, UPV, UAB, UBA, Chile, Los Andes, UCLA, Stanford, UDELAR, Sorbonne Nouvelle...) y soportes, entre otros: Surviving forced Disappearance in Argentina and Uruguay (Palgrave Macmillan, 2014), Identidades desaparecidas (Prometeo, 2012), El detenidodesaparecido (Trilce, 2008), y varios artículos en más de un idioma.

Resumen: A partir de una revisión de propuestas pasadas sobre la vida social en zonas alejadas de los sentidos normativos sobre la vida social ordinaria, el texto traza un recorrido que pasa por las tensiones entre representación y realidad, el testimonio y la víctima. En el límite, propone una figura teórica:la víctima pura, una suerte de doliente sin voz y plantea algunas dudas sobre las posibilidades reales de hacer investigación social sobre ella.

Palabras clave: Víctimas, testimonio, representación, vacío social.

\begin{abstract}
From a revision of past proposals about life in distant areas from the normative senses about everyday social life, the text traces a way from the tension between representation and reality, the testimony and the victim. At the limit suggests a theoretical figure: the pure victim, a kind of mourner without voice. It lays out out some questions about the real possibilities of making social investigation about her.
\end{abstract}

Key words: Victims, Testimony, Representation, Social Vacuum. 


\section{En la nada, intentando escuchar al actor social (o a alguien que se le parezca) ${ }^{1}$}

¿Cómo se lleva un trabajo de representación como el que propone la sociología a terrenos donde la palabra rebota? ¿Cómo hablar de lo que no se puede hablar? ¿Qué ciencia hacer cuando el objeto que se quiere trabajar escapa de la ciencia? ¿Existe propiamente hablando sentido cuando lo que sucede, fiesta o muerte, placer o desastre, en fin, cuando lo que hay es exceso, lo supera? Las preguntas, estas y otras, no son nuevas, no lo pretendo. Es más, hasta son pesadas de tan viejas: atraviesan la historia de las ciencias sociales desde que nacieron y se han multiplicado cuando las han hecho suyas las ciencias humanas. Son un lugar común, vaya, como lo son Auschwitz, el horror nazi, la ESMA, Abu Graib, Guantánamo, la frontera mexicana con los USA... como lo es casi todo el Siglo XX. Y no paro de encontrar libros y revistas sobre representación y memoria y testimonio. Una y otra vez. Una y otra vez. Adorno y el fin de la poesía. Una y otra vez. CLAUDE Lanzmann. Una y otra vez Primo Levi y la paradoja del testigo. Pero es llamativo que el tema, aunque lo sepamos marmotoso y recurrente siga interesando, y atrape. Sea con Giorgio Agamben, o con Jeffrey Alexander, o con Georges Didi Huberman, o con JeanLuc Nancy, o con Judith Butler... Da igual: la pregunta por los límites de la representación y por cómo estalla la palabra cuando roza lugares donde no debería entrar es de esas cosas que a aquel (Rudolf Otto (2000) le hizo pensar en lo sublime y en lo ominoso, lo fascinans y lo tremendum, que suele ser la misma cosa.

En lo que hace a mi experiencia de investigación, no he visitado ni la ESMA ni lo que queda de Auschwitz. De la primera estuve cerca, muy cerca, muchas veces además. Del segundo no. He leído de ello, claro, y he visto también muchas muestras de fotos y de arte dedicado a eso y a cómo problematizarlo. Muchos colegas han hablado de eso. Los he leído. Mi mesilla de noche rezuma de literatura del paso por el horror. No puedo con toda, pero lo poco con lo que puedo de literatura pasa por ahí. Pero nada de eso es realmente mi campo. Lo mío han sido, al menos desde 2002, las víctimas. Primero los desaparecidos (Gatti, 2008 y 2014a), luego las víctimas, sin más (2014b). Me interesan por muchos motivos, pero hay solo uno que hace al caso y que justifica que para hablar del testimonio pueda tener algo que decir a partir de lo que he trabajado en el pasado.

Se trata de cómo hacer para trabajar cuando no queda nada: ¿qué actor -si hay- buscar? ¿qué palabra -si tiene- darle? ¿Cómo mostrarlo? ¿Qué apuestas teóricas hacer? ¿Con qué estilos comprometerse? He trabajado en el pasado con desparecidos y con lo que queda de y tras ellos. Más

\footnotetext{
${ }^{1}$ Muchos argumentos de este trabajo proceden de reflexiones desarrolladas junto al equipo del proyecto "Mundo(s) de víctimas" (CSO 2011-22451). Con igual pretensión (reconocer) debo citar otras dos instancias: el grupo consolidado del Sistema Universitario Vasco (IT706-13) y el LALS de la Universidad de California en Santa Cruz, donde redacté este texto gracias a la correspondiente ayuda a la movilidad del Gobierno Vasco.
} 
cerca en el tiempo, con víctimas. Los dos complicados, muy complicados, de abordar para quien es presa de los rigores de las ciencias sociales, que no sirven para situaciones y figuras tan vidriosas. ¿Cómo desplegarse en ellas? ¿Qué obligaciones debemos respetar? No hablo de las obligaciones morales, no, aunque también podrían ponerse dentro del paquete. Hablo de las teóricas y las metodológicas, esto es, de la necesidad de pensar a estos vivos murientes y a estos muertos en vida dejándolos en el lugar que ocupan, uno donde dolor, sufrimiento, ajenidad, extrañeza... son las palabras clave, sin forzar a que salgan de ahí para hacerlos más normales y aprehensibles, para que sufran menos también, puede ser, pero al precio de desvirtuarlos. Se trata, sí, de la obligación de acercarse al lugar que ocupan (uno sinsentidioso, roto, quebrado, no normativo) sin forzarlos a pasar la frontera de lo común para hablar de ellos o con ellos.

Son figuras, en efecto, incómodas, y por eso, interesantes, viven en un lugar donde los que ordinariamente funciona no lo hace. Las técnicas de aprehensión del sentido ordinario no funcionan bien con ellas, las atrapa, pero solo parcialmente. Su palabra es rara, quebrada, cuando habla, su cuerpo se mueve mucho y gime. Viven en un lugar raro, el vacío social, la nada. ¿Quién hay ahí? ¿Qué estatuto tiene? Hablan distinto. Mucho de los que en ellas sustantivo tiene que ver con la enorme dificultad que producen en el lenguaje, que ante él rebota o se comprime. Se queda mudo. Si fuese poeta inventaría un lenguaje para este deslenguaje; si artista representaría lo irrepresentable; si novelista viajaría hasta los límites de lo inefable. Pero soy sociólogo, y la sociología - ya digo- se lleva mal, muy mal, con lo que se le escapa, se atormenta si topa con figuras o situaciones que huyen de su forma de representar, tan esférica, tan rotunda ¿Qué hacer?

En este texto repasaré primero, en modalidad esquema, la densidad específica de la vida social a la que hace referencia el concepto de vacío social; luego -y no muy ordenadamente- me preguntaré por tres cosas de ese lugar, si es que lo es, el vacío: quién vive allí (diré que la víctima), cómo habla (diré que por el testimonio), y cómo acercarse a eso desde fuera. De esto no sé qué diré, salvo que cerraré el texto presentando un personaje, la "víctima pura", lleno de problemas: no tiene nombre, no tiene forma, no tiene discurso, pero, ¡ay!, sin embargo existe.

\section{El vacío social}

Estoy convencido de que hoy el campo de trabajo más interesante para las ciencias sociales está en los lugares y entre los personajes que se le rebelan, que desertan, que las eluden, que huyen de nuestros conceptos para atrapar la realidad. Que allí donde las ciencias sociales no alcanzan a ver, existen cosas y que la naturaleza de esas cosas viene de las ciencias sociales no pueden representarlas. Han sido hasta 
ahora cinco las apuestas que he hecho para resolver ese galimatías: lo social vacío de sociedad y de sociología; el vacío social; las narrativas del sentido y de la ausencia de sentido; el trabajo del sociólogo ante las víctimas. Con ninguna solucioné nada. A las dos primeras les pesa la pecaminosa juventud y sus excesos. En el resto aparecen detalles que quisiera rescatar ahora: una cierta utilidad empírica, ciertas virtudes que los hacen rescatables como herramientas de trabajo para operar con situaciones concretas: la identidad del sufriente, la palabra del que la perdió, la vida social cuando ya no parece posible, la estructura de la catástrofe...

Trabajé hace años ya sobre el vacío social, y sobre lo social que despeja la sociología. Le di vueltas, con errores, a las estrategias para acercarse a la vida social cuando la sociología no la ve, y le di vueltas (2002) a una idea poderosa de Yves Barel, la de la invisibilidad social. Era fácil de ver, paradójicamente: son lugares que existen pero que no se ven, espacios, decía Barel, dotados de una cierta "mala voluntad para dejarse fijar en un lugar donde 'la sociedad' está segura de encontrarlos (...); son las miles de maneras de ausentarse del juego y de la escena sociales" (1982: 101). Cabe de todo ahí, cualquiera que juegue "a contrapié de las categorías" (ibídem: 95), que deserte de las clasificaciones disponibles, que tenga poca forma. Con los años lo fui redondeando un poco y sin dejar de acompañar a Barel lo nombré, primero, como "social vacío de sociedad y de sociología” $(2002,2003)$ y luego como "vacío social”. Lo primero, puedo decirlo ahora, no era muy operativo, aunque reivindico el estilo, la geometría enrevesada de la definición:

Lo social vacío de sociedad y de sociología es lo social como objeto no sociológico, o, lo que es lo mismo, el noobjeto como objeto. Es un lugar que es nosociológico porque no es susceptible de análisis desde las prácticas de representación propias de las modalidades fuertes, para las que resulta invisible; y un lugar, que es, no obstante, social, pues ha nacido por efecto del saber sociológico, de su eficacia y de su performatividad: es consecuencia y residuo del saber sociológico, y resulta, por lo demás, habitable como tal. (...) El concepto es (...) una advertencia: la de la existencia de cosas -y personas, y redes, y experiencias - a las que nos cuesta llegar con los instrumentos y procedimientos de los que los sociólogos disponemos para analizar nuestro objeto, procedimientos que producen esas cosas, cosas que, además, encuentran parte de su naturaleza en la huida de tales procedimientos. Advertencia, entonces, de que de la arquitectura que soporta el edificio del saber no sólo se ha escapado parte de la realidad, sino que precisamente es esa huida lo que da forma a la especificidad de esta parte fugada. (Gatti, 2003)

Tiene su belleza, perfila un territorio, define fronteras de un espacio interesante, el de los monstruos, animales y mendigos, el de los residuos de la representación, y señala en cada coma que es necesariamente paradójico hablar de ello. Pero ¿quién vive ahí? Ni modo ¿Cómo habla? No hay cómo saberlo. La estructura del concepto es onanista: no permite ir más allá de sí misma.

El de vacío social, de nuevo inspirado por Barel (1984), fue el concepto alternativo. Partía (Gatti, 2005) de un problema concreto, histórico, de época: la convicción extendida en ciencias sociales de que 
la vieja sociedad se desvanece, muerta por vaciamientos: lo que antes había, ahora no lo hay y queda solo el movimiento de su desaparición, el de la desvinculación, la desorientación, que es desinstitucionalización y desanclaje y desapego. Queda el movimiento de los DES- (agreguen ustedes lo que quieran tras este prefijo, verán que funciona). Quise pensar luego en qué era lo que había cuando lo que hubo ya no estaba; o sea, pensar en qué contiene el vacío de sociedad. Porque contiene algo pero lo que contiene no es como era lo que antes había ni como eran antes las cosas: queda la ausencia (de Estado, de ciudadanía, de identidad, de territorio...).

Y no sabemos trabajar con esos huecos. Cuando los vemos pensamos en rellenar de nuevo lo vacío, es una operación interesante desde el punto de vista analgésico pero pobre desde el intelectual: como ya no hay, pongo. ¿Pero y si lo que hay es, justamente eso, el vacío de lo anterior, si es eso lo que tenemos que intentar entender? No es esa la opción general: cuando encontramos vacíos caemos presa del horror vacui y metemos ahí, en eso, paladas de sentido: nuevas filiaciones si hay desafiliación, nuevas instituciones si lo que encontramos es desinstitucionalización, identidades redondas y rotundas ante la desidentificación... Frente a lo DES-, lo RE- Es algo así como una pulsión, pero no universal, apenas moderna.

¿Cabe pensar de otro modo? Cabe ¿Cabe hacer sociología (es decir, investigación social empírica)? Cabe, pero no hay muchos instrumentos para entender un mundo que se vacía y los personajes que viven en él, gestionando el sinsentido. Somos despiadados en ciencias sociales con lo sinsentidioso y eso nos pesa ahora. Con "vacío social” aspiraba a hacerlo, y lo proponía en cuatro pasos. El primero era su definición:

[Si el vacío en física es] un sitio existente, lleno de cosas, pero sitio y cosas a las que no se puede acceder directamente pues su inaccesibilidad es su rasgo más marcado (...), el vacío social se refiere a aquellas figuras y dimensiones de la vida colectiva que, aunque existentes, aunque habitables, aunque dotadas de cierta materialidad, no pueden ser representadas pues escapan de la lógica que estructura los mecanismos de representación de la vida en sociedad (...). El trabajo que requiere acercarse a ese vacío es de los arduos, pues si a él no se puede acceder directamente, no quedará más remedio que analizar sus síntomas, rodearlo, bordearlo; no meterse de lleno en él, porque de hacerlo se llenará, sino preguntarse por lo que lo hace vacío y por cómo es que como vacío deviene social, habitable (Gatti, 2005).

El segundo paso, la crítica a algunas estrategias para su llenado y, por tanto, obliteración ${ }^{2}$. El tercero, poco importa aquí, es el síntoma. ¿Cómo sabemos que en algún lugar hay eso que estoy llamando vacío? Por la desesperación que lo circunda: la de los que no lo pueden gestionar, la de los que

\footnotetext{
2 "Las conservadoras, que dicen que no es relevante. Las progres o neorrománticas, que lo llenan de esperanzas de nuevos órdenes. Las sustantivas, que ven en el vacío el indicador de una nueva ontología (en general líquida). Las onanistas, que se enredan en la condición inobservable del vacío" (Gatti, 2005).
} 
no lo pueden (podemos) representar... Esa desesperación mella las palabras que se le acercan, que revelan su susto. Así, decimos del mundo que se DESacraliza, DESafecta, DESagrega, DESancla, que DESaparece, se DESapega, O SE DESinstitucionaliza, se DESmoraliza y se DESorienta, se DESpatrimonializa o se DESvincula, se DESafilia y se DESprotege, se DESterritorializa y DEStradicionaliza, se DESvincula, se DISocia, se DISloca... Nada queda. El diagnóstico DES- (Gatti, 2005) el propio de tiempos en los que los que administran y piensa "lo social" lo entienden por su progresivo vaciamiento de lo que antaño lo caracterizaba, y que se asustan por ello, revela que cerca, hay algo y ese algo no se parece a lo que fue. Pero haber, HAY algo.

\section{El testimonio como palabra propia del vacío social}

El cuarto paso para poder trabajar con el vacío habla ya de cómo acceder a ese algo es el que me interesa un poco más ahora. Habla de su problema metodológico, de lo difícil que resulta entrar, pensar, representar algo que se emplaza en lugares por definición ausentes de la posibilidad de ser representados. ¿Cómo trabajar con esa paradoja? ¿Qué palabra dar a lo que no tiene palabra? ¿Qué textura tiene lo que rechaza la idea de textura? ¿Tiene orden lo que no lo tiene? ¿Cuál es la palabra del que no dispone de ella?

Aparece por fin el testimonio, palabra, pero emitida por quien padece; trozo de discurso que produce "la realidad" pero una que no es como las otras. En la literatura sobre el Holocausto, el testimonio es una entrada de índice segura. ¿Cómo pensar esos “momentos en los que los actos renuncian a entrar en las palabras, en las inscripciones” (Dodier, 1990: 115)? ¿Qué ocurre con la representación cuando cesan sus mecanismos? Salido del horror, Primo Levi - es sabido, y seré breve por eso- afrontó esa cuestión al querer testimoniar de la zona gris del Lager, del campo de exterminio (1989: 31-62), un universo desierto y vacío, un espacio excepcional, inconmensurable. Con él, el núcleo problemático es siemrpe la "erosión semántica de los enunciados” (Grierson, 1999: 119), el crack al que somete al lenguaje. Lo dijo Primo Levi: "Nuestra lengua carece de palabras para expresar esta ofensa, la demolición de un hombre" (ibídem: 120). Agamben sistematizando a Levi -también es sabido y también seré breve-propone hablar de la paradoja de este, la "Paradoja de Lévi": (i) "El musulmán es el testigo integral” (2002: 85, 157, 172); (ii) “yo testimonio por el musulmán” (ibídem: 172). Esto es: quien puede hablar de eso no tiene palabra; quien tiene palabra no tiene nada que decir de eso. ¿De qué pueden hablar, entonces, los que experimentaron el horror sólo parcialmente? De la distancia, de la tensión, del hueco que se abre entre el hecho y quien lo sobrevive, los capaces de la representación del hecho. En ese hueco se sitúa el testimonio: en el borde del vacío, representando lo que le hace este a la palabra, romperla, quebrarla, hacerla dolorosa. 
El testimonio es, pues, la tensión entre los hechos y sus representaciones cuando la representación es imposible. Visto así, del testimonio no importa el grado de ajuste con que refleje la realidad de la que testimonia ("El testimonio no garantiza la verdad factual del enunciado" (Mate, 2003: 228)); lo que importa es que refleje la desesperación de no poder contar, la desesperación de querer dar palabras a un lugar del que la palabra es expulsada. Los testigos "testimonian de un testimonio que falta (...). [Dan] testimonio de la imposibilidad de testimoniar” (Agamben, 2002: 34). Es esta entonces la fórmula que nos acerca a una solución al problema metodológico del vacío social: hablar del vacío hablando de la imposibilidad de representarlo. No contar algo; contar la imposibilidad de contar; contar una catástrofe lingüística. No describir el vacío, sino la imposibilidad de describirlo. Con el testimonio el vacío se hace accesible al mostrarnos las llagas que el vacío deja en el lenguaje. Si la pregunta era “qué ocurre con la representación cuando cesan sus mecanismos?’ la respuesta es inscribir la ausencia de la representación.

Un discurso hace que la atención se fije en un lugar, tematiza un territorio, lo crea como campo de interés, como objeto. Construye lo que Schlanger llama un “espectáculo problemático” (1983: 129). El discurso del testimonio provoca que irrumpa lo que está vacío de lenguaje y de sociedad. Si es de sociología que hablamos, testimoniar del vacío social es tematizar el lugar para el que el lenguaje de la sociología se ha agotado.

En Argentina, quienes salieron - pocos- de los centros clandestinos de detención de la dictadura 1976-1983, de los chupaderos en la jerga de la propia maquinaria represiva, lugares donde se suprimía toda conexión con el exterior y el detenido-desaparecido entraba en un lugar cuya cotidianidad transcurría en "los confines más subterráneos de la crueldad y de la locura” (CONADEP, 1984: 59), lugares de reglas que rompen con la Regla, se llaman ex-desaparecidos. Son nuestros testigos, emiten testimonio. Dicen cosas como estas:

[Allí] se acabó la ley de la gravedad (Eex)

[Allí] no se aplicaban las reglas de afuera. Se pasaban todos los límites (Eex)

¿Qué es lo que no es transmisible? ¿Los muertos? ¿Los desaparecidos? ¿Las torturas? Todo eso se entiende. Digo, se entiende con la cabeza. ¿Qué es lo que no se entiende? No se entiende la anomia, no se entiende la falta de reglas (Eex).

El impacto está sobre los desaparecidos y ellos no pueden dar testimonio, no pueden hablar. Que lo estemos haciendo los que pasamos de alguna manera por los lugares por donde pasaron los desaparecidos me parece... falso (Eex), 


\section{Son ellos los testigos (Eex) ${ }^{3}$}

Hablan, hablan, hablan. No hablan de cualquier modo. A partir de las notas tomadas en el diario de campo de la investigación que dio lugar al libro El detenido-desaparecido (2008) redacté este pasaje:

Es ésa su identidad [la del testigo]: comunica datos, recoge datos, busca datos. Reconstruye hechos. Y mientras habla, el cuerpo del testigo se tuerce; llora; cierra los ojos, se repliega. Conecta con un lugar terrible; la forma de decirlo ha de serlo. No es puesta en escena. Explica los síndromes que otros han prescrito para su situación (culpa, sospechas...). Explica cómo se fue pensando como muerta, como exiliado, como superviviente, como testigo finalmente... Y llega al testimonio, su vida: el suyo, el de los otros, que recoge para encontrar verdad, verdad, verdad. Datos, detalles, nombres, lugares. Es la retórica del testigo. Y mientras la escenifica, sus ojos siguen cerrados. Son testigos, hablan así: "Entendemos que tal vez la función prioritaria nuestra es el dar testimonio (Eex).

Ocupa, en efecto, un lugar y lenguaje tan dolorosos como estructurados. Algo que también anotamos en el diario colectivo del proyecto Mundo(s) de víctimas observando la testificación de víctimas del franquismo en el I Congreso de Víctimas del Franquismo (Gatti, 2016):

Diario de campo. Abril de 2013. Rivas Vaciamadrid. Primer congreso de víctimas del franquismo

Parte del espacio y de la agenda del Congreso gire alrededor de instancias de testimonio, de artilugios pensados para canalizar correctamente la voz de las víctimas (Castillejo, 2013): en la entrada, un panel con fotos de víctimas del franquismo - el espacio del testimonio- invita a "todas las víctimas que lo deseen" a ser entrevistadas. Muchas lo hacen: las historias no son nuevas para ellas, ¿quizás sí que les interpelen como integrantes de la identidad de víctima? Ya en pleno desarrollo del congreso, la organización deja un tiempo para oír "La voz de las víctimas". En él, entrevistadas por cuatro "periodistas especializados", tres mujeres -dos de más de 70 años, una de más 80- y un hombre -de unos 60 años-, presentados al auditorio como "representativos de distintos tipos de víctimas", relatan su historia: qué pasó con sus padres o hermanos, cómo vivieron los supervivientes después de su muerte o desaparición, cómo les trataban en la escuela, cómo se vivía la lejanía de España desde el exilio... No es la primera vez que cuentan esto; ni siquiera son novatos en el relato de su tragedia ante un público tan numeroso; no diría tampoco que es la primera vez que hacen uso del género testimonial. Sus cuerpos manejan bien ese doloroso registro, el necesario para narrar a otro un sufrimiento ya muy incorporado: miradas perdidas movimientos espasmódicos, obligación de contar y pesar por hacerlo porque eso que pasó "no tiene nombre", balbuceos cuando la lengua roza la zona de dolor, ahí donde la palabra se desvanece y el gesto y la llaga y el cuerpo retorcido tienen que ocupar su lugar para poder decir algo. Saben lo que hacer; saben que su relato se requiere y que interesa. Aceptan el espectáculo y sin inmutarse, quizás sin entenderlo, consienten que la

3 Todas las citas proceden de entrevistas sostenidas con sobrevivientes (ex-detenidos desaparecidos) de centros clandestinos de detención argentinos o uruguayos. Las entrevistas tuvieron lugar en Buenos Aires o Montevideo entre 2005 y 2008. La referencia Eex refiere al tipo de entrevistado en la nomenclatura de aquella investigación, en este caso, ex detenidos-desaparecidos. 
moderadora de "La voz de las víctimas", una académica, felicite a la organización por haber organizado un 'talk show' de testimonios.

Redondas maravillas del sinsentido. Incoherencia convertida en lenguaje. Si lo que quería era acceder a la víctima por el testimonio pensando que ña víctima era la habitante del vacío social algo no va. Una -la víctima - se ha convertido en personaje; otro - el testimonio- se ha convertido en género, se ha instalado ya como el lenguaje de las víctimas.

\section{La víctima pura y los límites del testimonio}

Las víctimas han devenido personajes sociales de gran centralidad. Lo que dicen cuenta, su palabra se oye. Circula. Son, en efecto, un personaje. Eso no significa negar ni sufrimiento ni dolor ni padecimiento. Solo decir que aunque ocupen los cada vez más vastos y visibles territorios del dolor, el de las víctimas se ha convertido en un universo muy nutrido, lleno de dolores, y también de oficios, de técnicas, de discursos, de géneros, de modos de aparecer. Pero el concepto, o la figura misma si se quiere, es demasiado intensa como para que nos limitemos a abordarla con la mirada del científico social que sospecha (Gatti, 2014b). Lo merece pero también merece otra mirada atenta a una dimensión singular en esta figura y en quienes la habitan: que están en muchos aspectos por fuera del discurso, expulsados de él, ausentes de toda opción de representarlos.

Muchos de los que habitan la condición de víctima acceden a circuitos que les permiten obtener miradas, cuidado, reconocimiento e incluso palabra y si formulamos la pregunta "¿Puede hablar la víctima?" -estableciendo un paralelismo quizás evidente pero sin embargo plausible con aquella otra de Gayatry Spivak (Can the subaltern speak?) (2003) - responderemos que sí, que puede hacerlo siempre cuando lo haga bien: que denuncie, que testimonie, que se encabalgue siempre el quejido y/o en el combate. Como el subalterno, la víctima puede hablar... si habla adecuadamente. El testimonio se ha convertido en un recurso potente. Para las víctimas, es un recurso. Si no pueden hablar, pueden testimoniar. Si lo hacen bien (gimen, duelen, duelean, se quiebran...) serán reconocidas.

Pero otros muchos de los que habitan la condición de víctima no, radicalmente no tienen palabra. De nuevo no hablo de un problema moral: el de la necesidad o no de dar voz a esos que quedan fuera de toda voz. El debate es interesante y poderoso, y se activó hace muy poco -noviembre de 2015- cuando todos lloramos y homenajeamos e hicimos duelos por las víctimas del atentado yihadista en París, en noviembre de 2015, y nada de eso hicimos por las del Líbano, en la misma fecha, por las mismas causas. Pero no es al problema del duelo diferencial (Butler, 2015) al que apunto. Hablo, más bien, del problema

teórico y metodológico de la víctima cuando lo es a tal nivel que ninguna palabra tiene acceso a ella, que todo rebota en ella. Incluso la posibilidad del testimonio. ¿Existe alguien ahí, donde nada hay? ¿Hay una 
víctima pura? ¿Qué sentido tiene la vida -y la existencia y la palabra- de los que viven fuera de todo sentido? La pregunta por la posibilidad de que aquellos que viven fuera del discurso, fuera de la idea de vida, fuera de los géneros, fuera de los marcos con los que estructuramos sentido... construyan sentido y participen de la vida en común es una preocupación creciente en ciencias sociales ¿Tienen palabra los que han perdido la palabra? ¿Cuál? ¿Puede ser oída? ¿Tienen agencia los que han sufrido? ¿Cuál? ¿Es colectiva? La pregunta ha sido abordada desde las ciencias sociales, aunque desde lugares periféricos y con dificultades para encontrar respuestas. Una de ellas, quizás la más rica, ha venido de la mano de Veena Das y su trabajo sobre el sufrimiento social (Das et al., 1997). Otra gracias a los esfuerzos de Judith Butler para pensar a los habitantes del afuera y a los que viven en permanencia en los territorios del duelo (2006). En ambos casos lo que han conseguido se apoya en una verdadera osadía: pensar que es posible el sinsentido, saltarse el mandato que dice que allí donde algo quebró, tiene que resurgir el equilibro. Si falta identidad, identidad vendrá; si falta palabra, la reencontraremos. Mientras, la nada. Lo mismo como lo humano vulnerado, lo humano devastado: no es humano, y no siéndolo, careciendo entonces de palabra, de forma y de agencia reconocibles, la único que se puede hacer con ello es reencontrar el equilibrio perdido. Entre otros, Butler razona contraintuivamente y dice: lo humano en situación de devastación es radicalmente humano y en ese contexto se construyen agencia, palabra, identidad, sentido, aunque sean rotas, extrañas o devastadas.

Butler argumenta de este modo: lo humano es consustancialmente vulnerable, pues depende de otros, del cuidado de otros. Siendo así, quien sufre y/o está en posición de duelo (un doliente duelente) y expresa, por eso, su vulnerabilidad y extrema dependencia, es quien más humano resulta. De ese argumento se derivan dos primeras conclusiones, que hacen a cómo pensar teóricamente la figura de la víctima:

Todos los humanos somos víctimas. La precariedad es la condición de toda vida pues todos dependemos unos de otros y estamos luego necesitados de protección. En potencia, todos somos víctimas y/o protectores de víctimas.

Aquellos que experimentan con más intensidad la experiencia de la pérdida y de la vulnerabilidad son, por su extrema dependencia de otros (de aquellos por los que sufren, de aquellos que los protegen, de aquellos a quien protegen), los más humanos. El duelo es entonces un lugar de expresión de lo humano en toda su intensidad: muestra que dependemos de otros, a los que dolemos, los que nos duelen: “nos involucra en vidas que no son las nuestras, irreversiblemente, si es que no fatalmente" En el límite, el duelo es lo que nos hace humanos. En el límite, pues, quien más sufre es quien más humano es. 
Detrás de ese razonamiento que comparece una escala, una jerarquía, que Butler no enuncia como tal pero que puede sin embargo llamarse "Escala de Butler" 4 , pues en ella se inspira. Permite llegar, allá al final, en el extremo, a la víctima pura:

Posición 1: la víctima en grado cero, en potencia la humanidad misma, toda ella integrada por sujetos que somos potencialmente víctimas pues dependemos de otros, aquellos cuya pérdida nos hace sufrir. Todos, aunque nadie.

Posición 2: la víctima misma, es decir, quien es reconocido tal, aquella porción de la humanidad que sufre efectivamente la pérdida y está marcada por ese dolor y por todo lo que ese dolor (im)posibilita y que tiene a su alcance recursos para expresarlo, vehicularlo, sufrirlo (el duelo y las comunidades de dolor (Das, 2008)), decirlo (el testimonio, por ejemplo), ser oído y ser escrito (por científicos sociales, por psicólogos, por humanistas). Algunos, concretos, visibles, tangibles.

Posición 3: los que sufriendo no son reconocidos ni escuchados ni escritos ni representados, ni siquiera vistos. Es vida humana expulsada del común, "vida para la que no cabe ningún duelo”, vida sin obituario, vida, en fin que no vale la pena. Vida no reconocida como tal, que no tiene palabra, ni atención, ni cuidado, ni representación. Vida en estado animal, nuda vida (Biehl, 2009; Agamben, 1998) ¿Víctimas? No en puridad, pues no son reconocidas tales, pero sí en esta escala de Butler, donde ocupan un lugar, extremo, el de la víctima pura quizás: dolor inasistible, indecible. Total. Algunos, pero inconcretos, invisibles, intangibles. Existen pero no dicen anda y si dicen no puedo escucharlos.

¿Es "víctima" el nombre que toma lo humano devastado, tan devastado que no tiene ni nombre ni recibe llanto? ¿Tiene forma de testimonio su palabra? No, pues no tiene forma audible. A esos lugares en el pasado me acerqué forzando escrituras rotas. La idea es sencilla, y no es nueva: al rozarse con lo imposible -el horror, lo fluido, el límite, lo indeciso...- lejos de racionalizarlo o de huirle se le afronta con un lenguaje dotado de la consistencia de lo que se observa. A realidad indecisa, imágenes indecisas; ante el horror y el sinsentido, lenguajes que nos dejan ante el umbral del espanto. Si la realidad es precaria, fragmentaria, paradójica, también habrá de serlo la explicación que dé cuenta de ella. Pero cuando hago campo, me quedo corto. Hay un lugar al que no, no se llega...

En el trabajo de campo del proyecto Mundo(s) de víctimas pasé por varias situaciones que permitían intuir que estaba cerca, pero cuando me hablaban las víctimas me alejaba, cuando el discurso era escuchado y hecho para escuchar, cuando tomaba forma, me distanciaba, de nuevo. El siguiente

\footnotetext{
${ }^{4}$ La tal escala es una de las entradas del glosario colectivo que hemos elaborado como "guía de trabajo teórico” con el amplio y frondoso equipo de investigadores del proyecto "Mundo(s) de víctimas”, ya citado.
} 
Gabriel Gatti. Tiene [la] palabra la víctima pura[?]...

extracto del diario de campo refleja esa tensión. De nuevo, me quedo en el borde, sin poder entrar ahí. Desesperado de no poder contar. X me dijo esto:

Diario de campo. 21/6/2013 [11M] X, una víctima del 11M. ¿La víctima es un tipo de relato?

La junta directiva de la asociación $11 \mathrm{M}$, a mi petición, me dio los datos de dos víctimas asociadas al colectivo, ambas heridas en el atentado, ambas con secuelas, una con físicas la otra con psíquicas, ambas instaladas en el trauma (...). Una de ellas ha hecho público su dolor y su resiliencia; la otra no. Una cuenta su historia de secuelas: trauma, divorcio, cáncer, cuidar a la madre de una víctima, paciente de Alzheimer, cuidar el dolor de otros, resistir al dolor propio. Testimonia constantemente, donde se lo piden. La otra no. Rumana, emigrante sin papeles en 2004, residente en la periferia. Infinitamente triste.

La llamé dos semanas atrás y desde el principio se mostró muy dispuesta a hablar, donde quisiéramos, cuando quisiéramos Quedamos en Coslada, su pueblo de adopción, una parada después de Sta. Eugenia, dos después de El Pozo, a 15 minutos de Atocha. La idea era ir a su casa a media mañana, pero el día anterior me llama para adelantar la cita y cuando finalmente nos encontramos, en la parada de tren, me sugiere hacer la entrevista en un parque (dice tener que hacer otra entrevista después. No me queda claro que sea así, pero sí que apunta ya cuál es el punto fuerte de su relato: la obsesión misma por el relato). Durante la entrevista, el paso constante de trenes al fondo se impone. No se inquieta mucho por las razones de lo que hago, ni por el destino de sus palabras. Tampoco ella tiene otras razones que no sea la de contar: "Me canso mucho", me dirá al final, "pero me alivia, me alivia”. Tiene unos 45 años. No se le ven secuelas, más allá de la pérdida de audición en un oído. No sabría describir lo que cuenta, sí dar testimonio de que la circularidad de la estructura del relato te atrapa: no sale del tren, de la descripción de lo que vio (un tronco sin cabeza, cuerpos desnudos sangrando, una pierna gorda), de su terror permanente ante cualquier expectativa de catástrofe (en casa, en el metro, en un avión, pero también en la calle, en la escuela de su hijo, con su hijo...). Compulsivamente ve programas de desastres ("Plane disaster", creo, en Discovery channel), películas sobre el 11S (United 93), videos sobre el $11 \mathrm{M}$ y sus testimonios. Compulsivamente busca relatar su desventura. Desea, y lo desea de verdad, contarle a sobrevivientes del $11 \mathrm{~S}$ lo que le pasó y que le cuente cómo lo pasaron. Está atrapada y quiere salir... atrapándose más a través del relato. El relato es la clave. Lleva diez años haciéndolo.

Es un relato bien articulado: circular, desesperado, atrapante. Quiere ser escuchado, necesita ser escuchado. ¿Está hecho para ser escuchado? No debe presuponerse que cuando escribo esto supongo mala intención, engaño u ocultamiento. De ningún modo. Solo que como en otras ocasiones me encuentro aquí ante un testigo que ha hecho del "dar cuenta de" su oficio y que lo ha depurado. A diferencia de lo que encontré en Argentina -testigos que cuentan para que se juzgue, para que no se repita, para que se sepa- la vocación del relato de $X$ es otra: contar que sufre, que sufre una barbaridad, que no sale del agujero. No obstante, al igual que aquellos, cuenta para alguien: hoy para mí, pero casi a diario para médicos, psiquiatras, psicólogos, homeópatas franceses (sic), jueces, televisiones... Está dispuesta, debe, quiere, ha de ser constantemente peritada, auditada como víctima. De eso depende su condición.

$\mathrm{Al}$ irme me cuenta dónde me tengo que sentar en los aviones para ir más seguro. Se despide con un abrazo y cuando le doy mi tarjeta me pregunta si me puede llamar para seguir hablando. 
$\mathrm{X}$ roza los lugares que quiero tocar, tiene forma de sufrimiento. Nunca nos hemos dejado vivir a nadie allí. A los que están ahí, victimas puras ¿Quién las escucha? ¿Hablan? Si no lo hacen, de acuerdo, otros testimoniarán en su lugar, lo dijeron Levi y Agamben. Y si habla tiene cómo hablar para que la entendamos, testimoniando. Pero ¿y si habla distinto? ¿Qué hacer? ¿Qué hacer con ella, con el zombi, con el esclavo? ¿En qué registro moverse para trabajar con estos subhumanos? 


\section{Bibliografía}

Agamben, G (1998). Homo sacer. Valencia: Pre-Textos

Agamben, G (2002). El archivo y el testigo. Valencia: Pre-Textos.

Barel, Y (1982). La marginalité sociale. París: PUF.

Barel, Y (1984). La société du vide. París: Seuil.

Biehl, J (2005). VITA: Life in a Zone of Social Abandonment. Berkeley: University of California Press.

Butler, J (2006). Elpoder del duelo y la violencia. Buenos Aires: Paidós.

Butler, J. "Mourning becomes the law". Letter from Judith Butler, Paris, Saturday 14th November (2015).

Castillejo, A. "Voces (en la cabeza): espacialidad, confesión y las mediaciones tele-tecnológicas de la verdad." Papeles del CEIC (2013): 1-42.

Conadep (1984). Nunca más: Informe de la Comisión Nacional sobre la Desaparición de Personas. Buenos Aires: CONADEP.

Das, V (2008). Sujetos del dolor, agentes de dignidad. Bogotá: Pontificia Universidad Javeriana.

Das, V., Kleinman, A y Lock, M (1997). Social suffering. Berkeley: University of California Press.

Dodier, N. "Représenter ses actions", Raisons Pratiques 1 (1990).

Gatti, G (2002). Las modalidades débiles de la identidad. Sociología de la identidad en los territorios vacíos de sociedad y de sociología. El caso del aprendizaje de euskera por adultos. Leioa: Universidad del País Vasco (serie "Tesis doctorales”).

Gatti, G. "Las modalidades débiles de la identidad. De la identidad en los territorios vacíos de sociedad (y de sociología)”. Política y Sociedad, 40/1 (2003): 87-109

Gatti, G. 2005. "La teoría sociológica visita el vacío social (o de las tensas relaciones entre la sociología y un objeto que le rehúye)". A. Ariño (coord.), Las encrucijadas de la diversidad cultural. Madrid: CIS

Gatti, G (2008). El detenido-desaparecido. Narrativas posibles para una catástrofe de la identidad. Montevideo: Trilce.

Gatti, G (2014a). Surviving forced disappearance in Argentina and Uruguay. Identity and Meaning. Nueva York: Palgrave MacMillan. 
Gatti, G. "Como la [víctima] española no hay (Pistas confusas para poder seguir de cerca y entender la singular vida de un personaje social en pleno esplendor)”. Kamchatka: revista de análisis cultural 4 (2014b): 275-292.

Gatti, G. "'Lo nuestro, como en Argentina'. Humanitarian Reason and the Latin Americanization of Victimhood in Spain”. Jounal of Latin American Cultural Studies (2016): 25-1

Grierson, K. “Indicible et incompréhensible dans le récit de déportation”. La Licorne (1999) : 51

Mate, R (2003). Memoria de Auschwitz. Madrid: Trotta.

Otto, R (2000). Lo santo. Madrid: Círculo de Lectores.

Schlanger, J (1983). Penser la bouche pleine. París: Fayard.

Spivak, G. “¿Puede hablar el subalterno?”. Revista colombiana de antropología 1 (2003): vol.39 